\title{
Design of Robust Controller for Higher Order Interval System Using Differential Evolutionary Algorithm
}

\author{
D. Srinivasa Rao', M. Siva Kumar ${ }^{2}$, M. Ramalinga Raju ${ }^{3}$ \\ ${ }^{1}$ Department of Electrical and Electronics Engineering, Gudlavalleru Engineering College (A), Gudlavalleru, AP, India \\ ${ }^{2,3}$ Department of Electrical and Electronics Engineering, University College of Engineering, JNTU University,
} Kakinada, Kakinada, AP, India

\begin{tabular}{l} 
Article Info \\
\hline Article history: \\
Received Jul 7, 2018 \\
Revised Sep 4, 2018 \\
Accepted Sep 20, 2018 \\
\hline
\end{tabular}

Keyword:

Differential

Algorithm

Interval System

Kharitonov's Theorem

Model Order Reduction

Robust Controller

\begin{abstract}
This paper describes the design of the robust PI/PID controller for the higher order interval system via its reduced order model using the differential evolution (DE) algorithm. A stable reduced interval model is generated from a higher order interval system using the DE in order to minimize the cost and reduce the complexity of the system. This reduced order interval numerator and denominator polynomials are determined by minimizing the Integral Squared Error (ISE) using the DE. Then, using reduced order interval model, a robust PI/PID controller is designed based on the stability conditions for determining robust stability of interval system. Finally, using these stability conditions, a set of inequalities in terms of controller parameters is obtained from the reduced order closed loop characteristic polynomial. Then these inequalities are solved to obtain robust controller parameters with the help of a DE algorithm. The designed, robust controller from the reduced order interval model will be attributed to the higher order interval system. The designed PI/PID controller from our proposed method not only stabilizes the reduced order model, but also stabilizes the original higher order system. The viability of the proposed methodology is illustrated through the numerical example of its successful implementation. The efficacy of the proposed methodology is also evaluated against the available approaches presented in the literature and the results were successfully implemented.

Copyright (C) 2018 Institute of Advanced Engineering and Science. All rights reserved.
\end{abstract}

\section{Corresponding Author:}

D. Srinivasa Rao,

Department of Electrical and Electronics Engineering,

Gudlavalleru Engineering College (A), Gudlavalleru AP, India.

Email: profsivakumar@gmail.com

\section{INTRODUCTION}

In most of control engineering problems, design and development of a controller are an important part among the researchers, because the simulation and design of a controller of the higher order system is not an easy task. The cost and complexity of the controller increase with system order. To conquer this problem of simulation, analysis and design of a controller for the higher order system, a reduced order model is essential for the original higher order system. In the closed loop system, a controller designed for this low order reduced model, will also stabilize the original higher order system. Hence, from the last three decades, model order reduction of the higher order system is an important aspect for researchers. For this reason, many methods are available for lower order models which are expected to approximate the performance of a higher order of linear time invariant system. Various model order techniques have been proposed for the order reduction of higher order continuous time as well as discrete-time systems. Among these methods, the familiar and important methods are discussed here. An aggregation method was 
proposed control the large scale dynamic system [1]. Pade approximate method [2] has very useful features for research due to being computationally simple. But the approximant obtained by this method often leads to be unstable even though the original system is stable. In view to conquer the problem of stability, the Routh approximation method [3] was introduced. But, the Routh approximation method fails to give well approximate at the low frequency level of the higher-order system. Several methods [4]-[7] have been given to improve the Routh approximation method for obtaining a reduced order model. All these methods are available for systems with fixed coefficients only. However, many control engineering problems like flexible manipulator system or nuclear reactor system represented by their mathematical model in a wide range of unknown operating conditions are bound under a certain amount of uncertainty. These uncertain parameters can be represented by bounded interval. This motivates researchers for an invention of the classical techniques for interval systems, or even for more general uncertain systems. Since last decade, much effort has been made in the design, simulation and control of plants with parametric uncertainty. Unfortunately, there are few methods available in the literature for the design of plants with parametric uncertainty through model order reduction in the entire range of operation. Some of the model reduction methods for fixed co-efficients mentioned above are extended to order the reduction of higher order interval systems through interval arithmetic to derive lower order approximates. Routh approximation technique [8] based on the direct truncation of the Routh table for interval systems using interval arithmetic and extending the Routh-Pade approximation reduction technique [4] to the interval system. Hwang et al.,[9] pointed out that this method has sometimes failed to generate stable reduced order interval models for stable original systems. To improve the effectiveness of order reduction of interval systems, many mixed methods are proposed in [10]-[12]. The stability analysis of interval polynomial was presented in [13] using Hurwitz polynomial.

In the area of control engineering, a very less work has been made in the design of controller for higher order systems using model order reduction technique. Hence, it is essential for researchers to design a controller for the higher order system through the reduced order model. Here few methods are introduced in the design of controllers which are available in the literature. From Lower order generalized aggregated model [14], a stabilizing controller is designed for the reduced order model, if applied to its original higher order system; it does not always guarantee the stability of its closed loop system. A lower order control technique proposed [15] using a model order reduction of an optimal closed loop system. But from this control technique, the higher order system stability not retained for a stable original system. Most of research work has carried out in this direction and a few methods are available. A controller scheme [16] is proposed, which is restricted to particular Davison reduced order model only and requires the system states to be available for feedback. Certain stability conditions are mentioned in [17] that the controller designed is not only stabilizes the reduced order model but also stabilizes the original higher order system. He also showed that the approximate inclusion of any unstable real modes of the higher order system in the lower order model will retain the existence of such simultaneous stabilizing controller. A special care for any model reduction scheme [18] has taken to obtain stabilizing controllers from a reduced order model. In the direction of Arno Linnemann, a dominant pole retention technique [19] is presented in a controller design for continuous time systems through reduced order model. All these available methods are used only for fixed coefficients of a polynomial/system.

In control engineering applications, tuning of PI, PID and lag/lead controllers have been widely used in industries for several decades. However, many important results have been recently reported on computation of all stabilizing P, PI and PID controllers in [20]-[22]. These controllers are widely used in various process control applications. The controller performance was compared based on settling time, percent of overshoot and stability analysis of a given system with fixed coefficients. But, many control engineering problems represented by their mathematical model in a wide range of unknown operating conditions are bound under a certain amount of uncertainty. The large uncertainty present in the control system causes degradation of system performance and destabilization. The model is known approximately and hence it is necessary to incorporate the robust in design. Therefore, robust control present in these uncertainties is very important for plant operation under stabilized condition. This necessitated a robust controller design which could stabilize the plant for all the operating conditions. Hence designing a robust controller for parametric uncertain plants having unknown, but bounded parameter uncertainties has become the problem of research nowadays. To minimize the stated uncertainties, many solutions were proposed in the literature for the simulation, design and tuning of controllers [23]-[24]. Recently, affordable results have been reported on computation of all stabilizing P, PI and PID controllers. Therefore, after the renowned theorem of Kharitonov [13], the stability analysis of polynomials due to parameter uncertainty has an important aspects of researchers. As per Kharitonov, the interval polynomial which assesses robust stability conditions that four specially constructed extreme polynomials are Hurwitz. Robust stability of

Design of robust controller for higher order interval system using differential ... (D. SrinivasaRao) 
interval polynomial is also discussed by many researchers'. In [25], necessary and sufficient stability conditions for interval polynomials are proposed using the results of [26] for fixed polynomials.

In this paper, model order reduction of interval systems is carried out by using the Kharitonov's polynomial [13] and differential evolution [27] using the ISE method. The numerator and denominator polynomials of the reduced model are obtained by minimizing integral squared error between the transient response of the original higher order system and the reduced order model pertaining to a unit step input. Thus, the stability is guaranteed for the reduced order system if the original higher order system is stable and the responses matching between original higher order system and the reduced order model. Then a PI/PID controller is designed for reduced lower order interval process plant based on the necessary and sufficient stability conditions [28]. These conditions are used to derive a set of inequalities in terms of controller parameters. The inequality constraints in the polynomial are solved consequently to obtain the controller parameters with the help of DE. The PI/PID controllers designed in this proposed method not only stabilizes the reduced order model, but also the original higher order system. The efficacy of the proposed method is demonstrated by implementing with a typical numerical example available in the literature. In comparison with the methods available in the literature [23], the proposed method in this paper is simple and involves less computational complexity. This paper is organized as follows: Section 2 gives robust of stability conditions of interval polynomial. Section 3 presents the problem formulation and the proposed order reduction algorithm. Section 4 proposes the design procedure for robust stabilizing PI/PID controller in section 5 proposed method is applied to design a robust PI/PID controller for higher order interval process plant with a suitable numerical example and the final conclusion is given in section 6 .

\section{ROBUST STABILITY CONDITIONS OF INTERVAL POLYNOMIAL}

Consider an interval polynomial ' $\mathrm{P}(\mathrm{s})$ ' of order $\mathrm{n}$ of the form given below.

$$
\mathrm{P}(\mathrm{s})=\mathrm{p}_{\mathrm{n}} \mathrm{s}^{\mathrm{n}}+\mathrm{p}_{\mathrm{n}-1} \mathrm{~s}^{\mathrm{n}-1}+\ldots+\mathrm{p}_{\mathrm{i}} \mathrm{s}^{\mathrm{i}}+\ldots+\mathrm{p}_{1} \mathrm{~s}+\mathrm{p}_{0},
$$

Where $p_{i} \in\left[a_{i}, b_{i}\right]$ for $\mathrm{i}=0,1,2,3, \ldots \ldots, \mathrm{n}$.

According to Anderson, Jury and Mansour [29] the necessary and sufficient condition for robust stability of interval polynomials of order $n \leq 3$ is positive lower bounds on the coefficients of an interval polynomial.Therefore, consider an interval polynomial of order $n=1$

$$
\begin{aligned}
& \mathrm{P}(\mathrm{s})=\sum_{\mathrm{i}=0}^{1} \mathrm{p}_{\mathrm{i}} \mathrm{s}^{\mathrm{i}}, \text { where } \mathrm{p}_{\mathrm{i}} \in\left[\mathrm{a}_{\mathrm{i}}, \mathrm{b}_{\mathrm{i}}\right] . \\
& \mathrm{P}(\mathrm{s})=\mathrm{p}_{1} \mathrm{~s}+\mathrm{p}_{0}=\left[\mathrm{a}_{1}, \mathrm{~b}_{1}\right] \mathrm{s}+\left[\mathrm{a}_{0}, \mathrm{~b}_{0}\right] .
\end{aligned}
$$

Therefore, as per Anderson et al., [29], the robust stability condition is

$$
a_{1}>0 \text { and } a_{0}>0 \text { i.e. } a_{i}>0 \text { for } \mathrm{i}=0,1 \text {. }
$$

Similarly for order $n=2$

$$
\mathrm{P}(\mathrm{s})=\sum_{\mathrm{i}=0}^{2} \mathrm{p}_{\mathrm{i}} \mathrm{s}^{\mathrm{i}}=\mathrm{p}_{2} \mathrm{~s}^{2}+\mathrm{p}_{1} \mathrm{~s}+\mathrm{p}_{0}=\left[\mathrm{a}_{2}, \mathrm{~b}_{2}\right] \mathrm{s}^{2}+\left[\mathrm{a}_{1}, \mathrm{~b}_{1}\right] \mathrm{s}+\left[\mathrm{a}_{0}, \mathrm{~b}_{0}\right]
$$

Therefore, the robust stability condition is

$$
a_{2}>0, a_{1}>0 \text { and } a_{0}>0 \text { i.e. } a_{i}>0 \text { for } i=0,1,2 \text {. }
$$

Lemma 2.1 Consider a real Hurwitz polynomial Q(s) of the form (1)

$$
\begin{aligned}
& Q(s)=\mathrm{q}_{n} \mathrm{~s}^{\mathrm{n}}+\mathrm{q}_{\mathrm{n}-1} \mathrm{~s}^{\mathrm{n}-1}+\ldots+\mathrm{q}_{\mathrm{i}} \mathrm{s}^{\mathrm{i}}+\ldots .+\mathrm{q}_{1} \mathrm{~s}+\mathrm{q}_{0} \\
& \mathrm{i}=0,1,2, \ldots \ldots . \mathrm{n}
\end{aligned}
$$

Where $\mathrm{q}_{\mathrm{i}}$ is real and positive, $\mathrm{q}_{0}>0$.

If any complex number $Z$ such that $R_{e}>0,|f(z)|>|f(-z)|$, moreover, $|f(z)|_{z o n ~ C}>|f(-z)|_{z o n}$, where $C$ is a Closed contour, then, according to Routhe's theorem [28] the following two polynomials can be formulated (2-3). 


$$
\begin{aligned}
& \mathrm{Q}_{0}=\left.\frac{1}{2}[\mathrm{Q}(\mathrm{s})+\mathrm{Q}(-\mathrm{s})]\right|_{\mathrm{s}^{2}=\mathrm{x}} \\
& \mathrm{Q}_{1}=\left.\frac{1}{2 \mathrm{~s}}[\mathrm{Q}(\mathrm{s})-\mathrm{Q}(-\mathrm{s})]\right|_{\mathrm{s}^{2}=\mathrm{x}}
\end{aligned}
$$

Theorem 2.1:For stability of $\mathrm{Q}(\mathrm{s})$ the two polynomials $\mathrm{Q}_{0}$ and $\mathrm{Q}_{1}$ formed by the alternate coefficients of a Hurwitz polynomial in accordance with equations (2) and (3) must have negative real zeros. The proof of this is given in [28].

\subsection{Necessary conditions for the stability of an interval polynomials}

Consider an interval polynomial of order $n>3$ of the form (4)

$$
P(s)=p_{n} s^{n}+p_{n-1} s^{n-1}+\ldots+p_{i} s^{i}+\ldots+p_{1} s+p_{0},
$$

Where $p_{i} \in\left[a_{i}, b_{i}\right]$ for $i=0,1,2,3, \ldots ., n$.

The necessary conditions for an interval polynomial to be stable is given as (5)

$$
b_{i} \geq a_{i}>0 \text { for } i=0,1,2,3, \ldots \ldots . . n .
$$

\subsection{Sufficient conditions for stability of interval polynomial for $\mathbf{n}>\mathbf{3}$}

A real coefficient interval polynomial of degree $n$ is of the form (6)

$$
\mathrm{P}(\mathrm{s})=\mathrm{p}_{\mathrm{n}} \mathrm{s}^{\mathrm{n}}+\mathrm{p}_{\mathrm{n}-1} \mathrm{~s}^{\mathrm{n}-1}+\ldots \ldots+\mathrm{p}_{1} \mathrm{~s}+\mathrm{p}_{0}
$$

Where $\mathrm{n} \geq 4$

$$
p_{O} \in\left[a_{0}, b_{0}\right], p_{1} \in\left[a_{1}, b_{1}\right], p_{2} \in\left[a_{2}, b_{2}\right], p_{3} \in\left[a_{3}, b_{3}\right], \ldots \ldots p_{n} \in\left[a_{n}, b_{n}\right]
$$

\begin{tabular}{|c|c|c|}
\hline Order of thePolynomial & Necessary Conditions & $\begin{array}{l}\text { Sufficient conditions } \\
\end{array}$ \\
\hline 3 & $\begin{array}{c}\qquad \sum_{0}^{n} a_{i}>0 \\
\text { Where i }=0,1,2,3\end{array}$ & $a_{1}^{2}>3 b_{0} b_{2}$ \\
\hline 4 & $\begin{array}{c}\sum_{O}^{n} a_{i}>0 \\
\text { Where i }=0,1,2,3,4 \text {. }\end{array}$ & $a_{2}^{2}>4 b_{0} b_{4}$ and $\frac{-a_{1}}{b_{3}}<0$ \\
\hline 5 & $\begin{array}{l}\sum_{O}^{n} a_{i}>0 \\
\text { Where } \mathrm{i}=0,1, .4,5\end{array}$ & $a_{2}^{2}>4 b_{0} b_{4}$ and $a_{3}^{2}>4 b_{1} b_{5}$ \\
\hline 6 & $\begin{array}{l}\quad \sum_{0}^{n} a_{i}>0 \\
\text { Where } \mathrm{i}=0,1, ., 5,6\end{array}$ & $a_{2}^{2}>3 b_{0} b_{4}$ and $a_{3}^{2}>4 b_{1} b_{5}$ \\
\hline 7 & $\begin{array}{l}\quad \sum_{0}^{n} a_{i}>0 \\
\text { Where } \mathrm{i}=0,1, ., 6\end{array}$ & $\mathrm{a}_{2}^{2}>3 \mathrm{~b}_{0} \mathrm{~b}_{4}$ and $\mathrm{a}_{3}^{2}>3 \mathrm{~b}_{1} \mathrm{~b}_{5}$. \\
\hline 8 & $\begin{array}{l}\sum_{0}^{n} a_{i}>0 \\
\text { Where i }=0,1, \ldots ., 7,8\end{array}$ & $a_{3}^{2}>3 b_{1} b_{5}, b_{4}^{2}>4 a_{0} a_{8}$ and $\frac{-a_{2}}{b_{6}}<0$ \\
\hline 9 & $\begin{array}{l}\quad \sum_{0}^{n} a_{i}>0 \\
\text { Where } \mathrm{i}=01, \ldots, 8,9\end{array}$ & $b_{4}^{2}>4 a_{0} a_{8} b_{5}^{2}>4 a_{1} a_{9}, \frac{-a_{2}}{b_{6}}<0$ and $\frac{-a_{3}}{b_{7}}<0$ \\
\hline 10 & $\begin{array}{l}\quad \sum_{O}^{n} a_{i}>0 \\
\text { Where i }=, 1,9,10\end{array}$ & $b_{4}^{2}>4 a_{0} a_{8}, b_{5}^{2}>4 a_{1} a_{9}, b_{6}^{2}>4 a_{2} a_{10}$ and $\frac{-a_{3}}{b_{7}}<0$ \\
\hline
\end{tabular}

Theorem 2.2: A real coefficient interval polynomial of degree $n \geq 4$ given in equation (6) is said to be robustly stable if and only if the following conditions are satisfied. Therefore, the necessary and sufficient conditions for stability of interval polynomials of order $n \geq 3$ are derived from [28] and they are presented in Table 1.

Table 1. Robust Stability conditions for various higher order interval polynomials 


\section{Proposed order reduction algorithm}

\subsection{Problem formulation}

Consider a higher order continuous time interval system given by the transfer function (7):

$$
G(s, C, D)=\frac{N(s, C)}{D(s, D)}=\frac{\left[C_{0}^{-}, C_{0}^{+}\right]+\left[C_{1}^{-}, C_{1}^{+}\right] s+\ldots \ldots+\left[C_{m}^{-}, C_{m}^{+}\right] s^{m}}{\left[D_{0}^{-}, D_{0}^{+}\right]+\left[D_{l}^{-}, D_{1}^{+}\right] s+\ldots \ldots+\left[D_{n}^{-}, D_{n}^{+}\right] s^{n}} m \leq n
$$

Where ${ }^{\left[C_{i}^{-}, C_{i}^{+}\right]}$for $i=0,1,2, \ldots, m_{\text {are numerator coefficients of } G(s, C, D)}$ with $C_{i}^{-}$and $C_{i}^{+}$as lower and upper bounds of interval $\left[\mathrm{C}_{\mathrm{i}}^{-}, \mathrm{C}_{\mathrm{i}}^{+}\right]$respectively, and $\left[\mathrm{D}_{\mathrm{i}}^{-}, \mathrm{D}_{\mathrm{i}}^{+}\right]_{\text {for }} \mathrm{i}=0,1,2, \ldots, \mathrm{n}$ are denominator coefficients of $\mathrm{G}(\mathrm{s}, \mathrm{C}, \mathrm{D}){ }_{\text {with }} \mathrm{D}_{\mathrm{i}}^{-}$and $\mathrm{D}_{\mathrm{i}}^{+}$as lower and upper bounds of interval $\left[\mathrm{D}_{\mathrm{i}}^{-}, \mathrm{D}_{\mathrm{i}}^{+}\right]$respectively.

It is desired to synthesize a robust controller for this higher order interval plant. This can be achieved by approximate the higher order plant into the reduced order model using the proposed model order reduction algorithm and a PI/PID robust controller is designed for the reduced order model using the proposed algorithm given in section 4. Finally the designed controller is attributed to the higher order system for robust stability.

The $\mathrm{k}^{\text {th }}$ order reduced interval model is obtained from our proposed method is given as (8)

$$
\mathrm{G}_{\mathrm{k}}(\mathrm{s}, \mathrm{c}, \mathrm{d})=\frac{\mathrm{N}(\mathrm{s}, \mathrm{c})}{\mathrm{D}(\mathrm{s}, \mathrm{d})}=\frac{\left[\mathrm{c}_{0}^{-}, \mathrm{c}_{0}^{+}\right]+\left[\mathrm{c}_{1}^{-}, \mathrm{c}_{1}^{+}\right] \mathrm{s}+\ldots \ldots+\left[\mathrm{c}_{\mathrm{k}-1}^{-}, \mathrm{c}_{\mathrm{k}-1}^{+}\right] \mathrm{s}^{\mathrm{k}-1}}{\left[\mathrm{~d}_{0}^{-}, \mathrm{d}_{0}^{+}\right]+\left[\mathrm{d}_{1}^{-}, \mathrm{d}_{1}^{+}\right] \mathrm{s}+\ldots \ldots+\left[\mathrm{d}_{\mathrm{k}}^{-}, \mathrm{d}_{\mathrm{k}}^{+}\right] \mathrm{s}^{\mathrm{k}}}
$$

Where $\left[c_{i}^{-}, c_{i}^{+}\right]$for $i=0,1,2, \ldots, k-1$ are numerator coefficients of $G(s, c, d)$ with ${ }^{\mathrm{c}_{\mathrm{i}}^{-}}$and $\mathrm{c}_{\mathrm{i}}^{+}$as lower and upper bounds of interval $\left[c_{i}^{-}, c_{i}^{+}\right]$respectively, and $\left[d_{i}^{-}, d_{i}^{+}\right]$for $i=0,1,2, \ldots, k$ are denominator coefficients of $G(s, c, d)$ with $d_{i}^{-}$and $d_{i}^{+}$as lower and upper bounds of interval $\left[d_{i}^{-}, d_{i}^{+}\right]$respectively.

\subsection{Order Reduction Of Interval System}

According to the Kharitonov's theorem, the interval system can be represented into four fixed parameter Kharitonov transfer functions. They are given as (9-12):

$$
\begin{aligned}
& G^{1}(s, C, D)=\frac{N^{1}(s, C)}{D^{1}(s, D)}=\frac{C_{0}^{-}+C_{1}^{-} s+C_{2}^{+} s^{2}+\ldots \ldots \ldots C_{m}^{-} s^{m}}{D_{0}^{-}+D_{1}^{-} s+D_{2}^{+} s^{2}+\ldots \ldots D_{n}^{-} s^{n}} \\
& G^{2}(s, C, D)=\frac{N^{2}(s, C)}{D^{2}(s, D)}=\frac{C_{0}^{-}+C_{1}^{+} s+C_{2}^{+} s^{2}+\ldots \ldots . C_{m}^{-} s^{m}}{D_{0}^{-}+D_{1}^{+} s+D_{2}^{+} s^{2}+\ldots \ldots D_{n}^{-} s^{n}} \\
& G^{3}(s, C, D)=\frac{N^{3}(s, C)}{D^{3}(s, D)}=\frac{C_{0}^{+}+C_{1}^{-} s+C_{2} s^{2}+\ldots \ldots \ldots C_{m}^{+} s^{m}}{D_{0}^{+}+D_{1}^{-} s+D_{2}^{-} s^{2}+\ldots \ldots D_{n}^{+} s^{n}} \\
& G^{4}(s, C, D)=\frac{N^{4}(s, C)}{D^{4}(s, D)}=\frac{C_{0}^{+}+C_{1}^{+} s+C_{2}^{-} s^{2}+\ldots \ldots \ldots C_{m}^{+} s^{m}}{D_{0}^{+}+D_{1}^{+} s+D_{2}^{-} s^{2}+\ldots \ldots . D_{n}^{+} s^{n}}
\end{aligned}
$$

The above four Kharitonov's transfer functions are, in general represented as (13)

$$
G^{i}(s, C, D)=\frac{N^{i}(s, C)}{D^{i}(s, D)} \text { for } \mathrm{i}=1,2,3,4
$$

These higher order four fixed parameter Kharitonov's transfer functions are approximated into the reduced order model using following procedure.Let the four fixed parameter reduced order models of the above equations (9-13) obtained by the proposed method are defined as (14-17) 


$$
\begin{aligned}
& \mathrm{G}_{\mathrm{k}}^{1}(\mathrm{~s}, \mathrm{c}, \mathrm{d})=\frac{\mathrm{n}_{\mathrm{r}}^{1}(\mathrm{~s}, \mathrm{c})}{\mathrm{d}_{\mathrm{r}}^{1}(\mathrm{~s}, \mathrm{~d})}=\frac{\mathrm{c}_{0}^{-}+\mathrm{c}_{1}^{-} \mathrm{s}+\mathrm{c}_{2}^{+} \mathrm{s}^{2}+\ldots \ldots . . \mathrm{c}_{\mathrm{k}-1}^{-} \mathrm{s}^{\mathrm{k}-1}}{\mathrm{~d}_{0}^{-}+\mathrm{d}_{1}^{-} \mathrm{s}+\mathrm{d}_{2}^{+} \mathrm{s}^{2}+\ldots \ldots \mathrm{d}_{\mathrm{k}}^{-} \mathrm{s}^{\mathrm{k}}} \\
& \mathrm{G}_{\mathrm{k}}^{2}(\mathrm{~s}, \mathrm{c}, \mathrm{d})=\frac{\mathrm{n}_{\mathrm{r}}^{2}(\mathrm{~s}, \mathrm{c})}{\mathrm{d}_{\mathrm{r}}^{2}(\mathrm{~s}, \mathrm{~d})}=\frac{\mathrm{c}_{0}^{-}+\mathrm{c}_{1}^{+} \mathrm{s}+\mathrm{c}_{2}^{+} \mathrm{s}^{2}+\ldots \ldots \ldots \mathrm{c}_{\mathrm{k}-1}^{-} \mathrm{s}^{\mathrm{k}-1}}{\mathrm{~d}_{0}^{-}+\mathrm{d}_{1}^{+} \mathrm{s}+\mathrm{d}_{2}^{+} \mathrm{s}^{2}+\ldots \ldots . \mathrm{d}_{\mathrm{k}}^{-} \mathrm{s}^{\mathrm{k}}} \\
& \mathrm{G}_{\mathrm{k}}^{3}(\mathrm{~s}, \mathrm{c}, \mathrm{d})=\frac{\mathrm{n}_{\mathrm{r}}^{3}(\mathrm{~s}, \mathrm{c})}{\mathrm{d}_{\mathrm{r}}^{3}(\mathrm{~s}, \mathrm{~d})}=\frac{\mathrm{c}_{0}^{+}+\mathrm{c}_{1}^{-} \mathrm{s}+\mathrm{c}_{2}^{-} \mathrm{s}^{2}+\ldots \ldots . \mathrm{c}_{\mathrm{k}-1}^{+} \mathrm{s}^{\mathrm{k}-1}}{\mathrm{~d}_{0}^{+}+\mathrm{d}_{1}^{-} \mathrm{s}+\mathrm{d}_{2} \mathrm{~s}^{2}+\ldots \ldots \mathrm{d}_{\mathrm{k}}^{+} \mathrm{s}^{\mathrm{k}}} \\
& \mathrm{G}_{\mathrm{k}}^{4}(\mathrm{~s}, \mathrm{c}, \mathrm{d})=\frac{\mathrm{n}_{\mathrm{r}}^{4}(\mathrm{~s}, \mathrm{c})}{\mathrm{d}_{\mathrm{r}}^{4}(\mathrm{~s}, \mathrm{~d})}=\frac{\mathrm{c}_{0}^{+}+\mathrm{c}_{1}^{+} \mathrm{s}+\mathrm{c}_{2}^{-} \mathrm{s}^{2}+\ldots \ldots . . \mathrm{c}_{\mathrm{k}-1}^{+} \mathrm{s}^{\mathrm{k}-1}}{\mathrm{~d}_{0}^{+}+\mathrm{d}_{1}^{+} \mathrm{s}+\mathrm{d}_{2}^{-} \mathrm{s}^{2}+\ldots \ldots . . \mathrm{d}_{\mathrm{k}}^{+} \mathrm{s}^{\mathrm{k}}}
\end{aligned}
$$

The above Four Kharitonov's transfer functions are, in general represented as (18):

$$
\mathrm{G}_{\mathrm{k}}^{\mathrm{i}}(\mathrm{s}, \mathrm{c}, \mathrm{d})=\frac{\mathrm{n}_{\mathrm{k}}^{\mathrm{i}}(\mathrm{s}, \mathrm{c})}{\mathrm{d}_{\mathrm{k}}^{\mathrm{i}}(\mathrm{s}, \mathrm{d})} \text { For } \mathrm{i}=1,2,3,4
$$

In this work, the numerator and denominator coefficients of the reduced model are obtained by minimizing the objective function ' $\mathrm{J}$ ', which is the error between the original higher order system and the reduced order system. Therefore, it is represented in the form (19):

$$
\mathbf{J}=\int_{0}^{\infty}\left(\mathrm{y}(\mathrm{t})-\mathrm{y}^{\mathrm{k}}(\mathrm{t})\right)^{2} \mathrm{dt}
$$

Mathematically the Integral Square error can be represented as (20)

$$
\mathrm{J}=\sum_{0}^{\mathrm{M}}\left[\mathrm{y}(\mathrm{t})-\mathrm{y}^{\mathrm{k}}(\mathrm{t})\right]^{2}
$$

Where, $y(t)$ is the unit step response of higher order and $y^{k}(t)$ is the unit step response lower order system at the instant in the time interval $0 \leq \mathrm{t} \leq \mathrm{M}$, where $\mathrm{M}$ is to be chosen. The objective is to obtain a reduced order model, which is closely approximate original system. The objective function is to minimize ISE by using DE.

\subsection{Proposed DE algorithm for order reduction}

DE is a stochastic, population based direct search optimization algorithm introduced by Storn and Price in 1997[27]. DE works with two populations; old generation and new generation of the same population. NP is the size of the population and it is adjusted. The population consists of real valued vectors with a dimension $\mathrm{D}$ that equals the number of design parameters/control variables. The population is randomly initialized within the initial parameter bounds. The three main operations carry optimization processes are: mutation, crossover and selection. In each generation, individuals of the current population become target vectors. For each target vector, the mutation operation produces a mutant vector. The crossover operation generates a new vector, called trial vectors, by mixing the parameters of the mutant vector with those of the target vector. If the trial vector obtains a better fitness value than the target vector, then the trial vector replaces the target vector in the next generation.

\subsubsection{Initialization:}

Define upper and lower bounds for each parameter of the reduced order model (21)

$$
X_{j}^{L} \leq X_{j, i, 1} \leq X_{j}^{U}
$$

Randomly select the initial parameter values uniformly on the intervals $\left[\mathrm{X}_{\mathrm{j}}^{\mathrm{L}}, \mathrm{X}_{\mathrm{j}}^{\mathrm{U}}\right]$, and the elements of each individual ${ }_{i, 0}^{j}$ are given by (22) 


$$
X_{i, 0}^{\mathrm{j}}=X_{\min }^{\mathrm{j}}+\operatorname{rand}\left(X_{\max }^{\mathrm{j}}-X_{\min }^{\mathrm{j}}\right)
$$

Where $i=1,2, \ldots, N$ and $j=1,2, \ldots ., D$.

Where $\mathrm{N}$ is the population size, rand $(0,1)$ is a random number uniformly distributed between 0 and $1, \mathrm{D}$ is the number of control variables.

\subsubsection{Mutation:}

Mutation expands the search space. DE undergoes mutation operation after initialization. In mutation operation, it produces mutant vector $\mathrm{V}_{\mathrm{i}, \mathrm{G}}$, with respective to each individual $\mathrm{X}_{\mathrm{i}, \mathrm{G}}$, so called target vector, in the current population via mutation strategy (23):

$$
V_{i, G}=X_{i, G}+F\left(X_{b e s t, G}-X_{i, G}\right)+F\left(X_{r l, G}-X_{r 2, G}\right) .
$$

For a given parameter vector $X_{i, G}$ two vectors $X_{r l, G}$ and $X_{r 2, G}$ are selected randomly such that the indices $\mathrm{r} 1, \mathrm{r} 2$ is distinct. The mutation factor $\mathrm{F}$ is a constant from $[0,2]$ is called the donor vector.

\subsubsection{Crossover:}

Crossover incorporates successful solutions from the previous generation. After mutation, DE undergoes crossover. The trial vector $\mathrm{U}_{\mathrm{i}, \mathrm{G}}$ is developed from the elements of the target vector, ${ }_{\mathrm{i}, \mathrm{G}}$, and the elements of the donor vector, $\mathrm{V}_{\mathrm{i}, \mathrm{G}}$ :

$$
\begin{aligned}
u_{i, G}^{j}= & v_{i, G}^{j} i f\left(\operatorname{rand}_{j}(0,1) \leq C R\right) \operatorname{or}\left(j=j_{\text {rand }}\right) \\
& =X_{i, g}^{j} \text { otherwise }
\end{aligned}
$$

Elements of the donor vector enter the trial vector with probability CR (cross over rate) set to [0; 1].

\subsubsection{Selection:}

The newly generated values of trail vectors exceed the corresponding upper and lower bounds; we initialize them randomly and uniformly within the pre-specified range (25):

$$
\begin{aligned}
X_{i, G}^{j}= & U_{i, g}^{j} \text { if } f\left(U_{i, G}^{j}\right) \leq f\left(X_{i, G}\right), \\
& =X_{i, g}^{j} \text { otherwise }
\end{aligned}
$$

The trail vector $\mathrm{X}_{\mathrm{i}, \mathrm{G}}$ is compared with trail vector $\mathrm{U}_{\mathrm{i}, \mathrm{G}}$ and the one with lowest function value is admitted to the next generation. Therefore the four $\mathrm{k}^{\text {th }}$ order reduced Kharitonov's transfer function denominators and the numerators are obtained by minimizing integral square error using Differential Evolution Algorithm.

Finally the reduced order interval model is obtained by the following equation (26):

$$
G_{k}^{i}(s, c, d)=\frac{\sum_{j=0}^{k-1}\left[\min \left(b_{i j}\right), \max \left(b_{i j}\right) s^{j}\right.}{\sum_{j=0}^{k}\left[\min \left(a_{i j}\right), \max \left(a_{i j}\right)\right]^{j}} \quad \text { For } i=1,2,3,4 .
$$

For this reduced order model, a PI/PID robust controller is designed based on the minimization of the objective function $\mathrm{J}=\left(\mathrm{K}_{\mathrm{P}}-\mathrm{K}_{\mathrm{P}}^{0}\right)^{2}+\left(\mathrm{K}_{\mathrm{I}}-\mathrm{K}_{\mathrm{I}}^{0}\right)^{2}$ for PI controller and $\mathrm{J}=\left(\mathrm{K}_{\mathrm{P}}-\mathrm{K}_{\mathrm{P}}^{0}\right)^{2}+\left(\mathrm{K}_{\mathrm{I}}-\mathrm{K}_{\mathrm{I}}^{0}\right)^{2}+\left(\mathrm{K}_{\mathrm{D}}-\mathrm{K}_{\mathrm{D}}^{0}\right)^{2}$ for PID controller using the same DE algorithm. 


\section{Design Procedure for Robust stabilizing PI/PID Controller}

Let the stabilizing controller $\mathrm{G}_{\mathrm{c}}(\mathrm{s})$ is considered to be a PI/PID controller transfer function of the form given below (27-28).

$$
\begin{aligned}
& G_{c}(s)=K_{P}+\frac{K_{I}}{s}=\frac{N_{c}(s)}{D_{c}(s)} \text { for PI controller } \\
& G_{c}(s)=K_{P}+\frac{K_{I}}{s}+K_{D^{s}}=\frac{N_{c}(s)}{D_{c}(s)} \text { for PID controller }
\end{aligned}
$$

Where $\mathrm{K}_{\mathrm{P}}=$ Proportional gain, $\mathrm{K}_{\mathrm{I}}$ =Integral gain and $\mathrm{K}_{\mathrm{D}}$ derivative gain.

Now the system with robust stabilizing controller for parametric uncertainty is as shown in Figure 1.

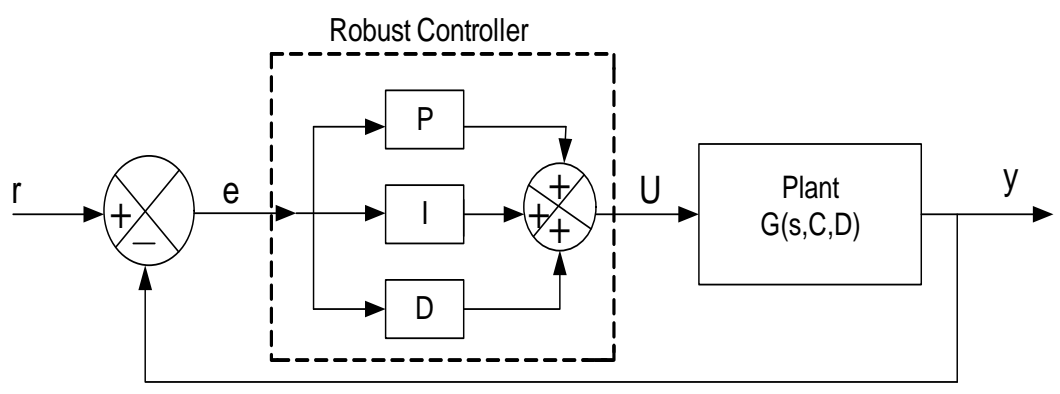

Figure 1. Block diagram of closed loop system with PI/PID controller

Then the closed loop transfer function with a PI / PID controller can be defined as (29)

$$
T(s)=\frac{G_{c}(s) G_{r}(s, c, d)}{1+G_{c}(s) G_{r}(s, c, d)}=\frac{N_{c}(s) N_{r}(s, c)}{N_{c}(s) N_{r}(s, c)+D_{c}(s) D_{r}(s, d)}
$$

Where $\mathrm{N}_{\mathrm{r}}(\mathrm{s}, \mathrm{c})$ and $\mathrm{D}_{\mathrm{r}}(\mathrm{s}, \mathrm{d})$ are the numerator and denominator polynomials of the reduced order interval plant, ${ }^{\mathrm{N}_{\mathrm{c}}(\mathrm{s})}$ and $\mathrm{D}_{\mathrm{c}}(\mathrm{s})$ are the numerator and denominator polynomials of $\mathrm{G}_{\mathrm{c}}(\mathrm{s})$ respectively. This PI/PID controller robustly stabilizes the interval plants family, if for all $c \in C$ and $d \in D$, then the characteristic polynomial of a closed loop transfer function given in equation (29) has all zeros have negative real values. Now apply the necessary and sufficient conditions of robust stability conditions given in Table. 1 to the closed-loop characteristic polynomial $\mathrm{N}_{c}(\mathrm{~s}) \mathrm{N}_{\mathrm{r}}(\mathrm{s}, \mathrm{c})+\mathrm{D}_{\mathrm{c}}(\mathrm{s}) \mathrm{D}_{\mathrm{r}}(\mathrm{s}, \mathrm{d})$ which leads to a set of constraints in terms of controller parameters. Then these constraints are solved by using DE so as to minimize the objective function $J=\left(K_{P}-K_{P}^{0}\right)^{2}+\left(K_{I}-K_{I}^{0}\right)^{2}$ for PI controller and $\mathrm{J}=\left(\mathrm{K}_{\mathrm{P}}-\mathrm{K}_{\mathrm{P}}^{0}\right)^{2}+\left(\mathrm{K}_{\mathrm{I}}-\mathrm{K}_{\mathrm{I}}^{0}\right)^{2}+\left(\mathrm{K}_{\mathrm{D}}-\mathrm{K}_{\mathrm{D}}^{0}\right)^{2}$ for PID controller to obtain controller parameters. Then after obtaining the controller parameters, form four sets of Kharitonov's polynomials [13] to check the stability and the closed-loop step response to verify the results.

Application of the DE algorithm for determining the controller parameters is as follows:

Step 1: Initialization:

Define upper and lower bounds for each controller parameter of the PI/PID controller (30)

$$
X_{j}^{L} \leq X_{j, i, 1} \leq X_{j}^{U}
$$

The initial parameter values are randomly selected uniformly within the allowable range (31)

$$
\left[X_{j}^{\mathrm{L}}, X_{j}^{\mathrm{U}}\right], X_{\mathrm{i}, 0}^{\mathrm{j}}=X_{\min }^{\mathrm{j}}+\operatorname{rand}\left(X_{\max }^{\mathrm{j}}-X_{\min }^{\mathrm{j}}\right)
$$


Where $I=1,2, \ldots, N$ and $j=1,2, D N$ is the population size, rand $(0 ; 1)$ is a random number uniformly distributed between 0 and $1, \mathrm{D}$ is the number of controller parameters. The minimum and maximum values of the control variables for PI/PID Controller i.e. $\mathrm{K}_{\mathrm{P}}, \mathrm{K}_{\mathrm{I}}$ and $\mathrm{K}_{\mathrm{D}}$ are selected as

$$
\begin{aligned}
& 0<\mathrm{K}_{\mathrm{P}}<10 \text { and } 0<\mathrm{K}_{\mathrm{I}}<5 \text { for PI controller. } \\
& 0<\mathrm{K}_{\mathrm{P}}<10,0<\mathrm{K}_{\mathrm{I}}<5 \text { and } 0<\mathrm{K}_{\mathrm{D}}<5 \text { forPID controller. }
\end{aligned}
$$

Step 2: Mutation

DE undergoes mutation operation after initialization. In mutation operation, it produces mutant vector $\mathrm{V}_{\mathrm{i}, \mathrm{G}}$, with respective to each individual $\mathrm{X}_{\mathrm{i}, \mathrm{G}}$, so called target vector, in the current population via mutation strategy (32):

$$
V_{i, G}=X_{i, G}+F\left(X_{b e s t, G}-X_{i, G}\right)+F\left(X_{r l, G}-X_{r 2, G}\right) .
$$

For a given parameter vector $\mathrm{X}_{\mathrm{i}, \mathrm{G}}$ two vectors $\mathrm{X}_{\mathrm{r} 1, \mathrm{G}}$ and $\mathrm{X}_{\mathrm{r} 2, \mathrm{G}}$ are selected randomly such that theindices $\mathrm{r} 1, \mathrm{r} 2$ is distinct. The mutation factor $\mathrm{F}=1.2$ is chosen from $[0 ; 2]$ is called the donor vector.

Step 3: Crossover

After mutation, DE undergoes crossover. The trial vector $U_{i, G}$ is developed from the elements of the target vector, $\mathrm{X}_{\mathrm{i}, \mathrm{G}}$, and the elements of the donor vector (33), $\mathrm{V}_{\mathrm{i}, \mathrm{G}}$ :

$$
\begin{aligned}
u_{i, G}^{j}= & v_{i, G}^{j} i f\left(\operatorname{rand}_{j}(O, 1) \leq C R\right) \text { or }\left(j=j_{\text {rand }}\right) \\
& =X_{i, g}^{j} \text { otherwise }
\end{aligned}
$$

Elements of the donor vector enter the trial vector with probability $\mathrm{CR}=0.6$ set from $[0 ; 1]$.

Step 4: Selection

The newly generated values of trail vectors exceed the corresponding upper and lower bounds; we initialize them randomly and uniformly within the pre-specified range (34):

$$
\begin{aligned}
X_{i, G}^{j}= & U_{i, g}^{j} \text { if } f\left(U_{i, G}^{j}\right) \leq f\left(X_{i, G}\right) \\
& =X_{i, g}^{j} \text { otherwise }
\end{aligned}
$$

The trail vector $X_{i, g}$ is compared with trail vector $U_{i, G}$ and the one with lowest function value is admitted to the next generation. Finally the results of the best parameters of a PI/PID controller and fitness are obtained

\section{NUMERICAL EXAMPLE}

Consider a wing aircraft [23] whose transfer function with parametric uncertainty is given (35)

$$
G(s, C, D)=\frac{[54,74] s+[90,166]}{s^{4}+[2.8,4.6] s^{3}+[50.4,80.8] s^{2}+[30.1,33.9] s+[-0.1,0.1]}
$$

The closed loop transfer function of the above interval system is given by (36)

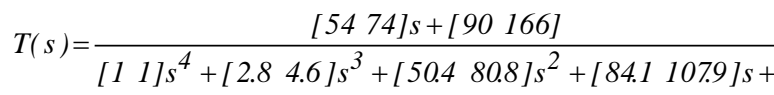

$$
\begin{aligned}
& \text { [89.9 1661] }
\end{aligned}
$$

This higher order closed loop transfer function of interval system can be represented as four fixed parameter Kharitonov transfer functions that are given as (37-40): 


$$
\begin{aligned}
& T_{1}(s)=\frac{54 s+90}{s^{4}+4.6 s^{3}+80.8 s^{2}+84.1 s+89.9} \\
& T_{2}(s)=\frac{74 s+90}{s^{4}+2.8 s^{3}+80.8 s^{2}+107.9 s+89.9} \\
& T_{3}(s)=\frac{54 s+166}{s^{4}+4.6 s^{3}+50.4 s^{2}+84.1 s+1661} \\
& T_{4}(s)=\frac{74 s+166}{s^{4}+2.8 s^{3}+50.4 s^{2}+107.9 s+1661}
\end{aligned}
$$

It is difficult to analyze the higher order system, because the cost and complexity of the higher order system increase with increase in order of system. The model order reduction is required for minimizing the cost and complexity of the higher order system. The numerator and denominator coefficients of the reduced order model are obtained by minimizing integral square error using the procedure given in section 3 and are available from the following Tables 2 and 3.

The four reduced order Kharitonov's transfer functions are (41-44):

$$
\begin{aligned}
& \mathrm{T}_{\mathrm{k}}^{1}=\frac{53.4014 \mathrm{~s}+90.1511}{79.4364 \mathrm{~s}^{2}+81.7131 \mathrm{~s}+89.7877} \\
& \mathrm{~T}_{\mathrm{k}}^{2}=\frac{73.2952 \mathrm{~s}+90.3032}{77.256 \mathrm{~s}^{2}+104.9378+89.5829} \\
& \mathrm{~T}_{\mathrm{k}}^{3}=\frac{59.9965 \mathrm{~s}+169.9494}{50 \mathrm{~s}^{2}+80 \mathrm{~s}+169.765} \\
& \mathrm{~T}_{\mathrm{k}}^{4}=\frac{84.9994+169.2678}{50 \mathrm{~s}^{2}+120 \mathrm{~s}+169.9993}
\end{aligned}
$$

\begin{tabular}{|c|c|c|}
\hline \multirow{2}{*}{ Name of polynomial } & \multicolumn{2}{|c|}{ ISE } \\
\hline & Maximum & Minimum \\
\hline First Kharitonov & $6.677 * 10-4$ & $2.4 * 10-3$ \\
\hline Second Kharitonov & 0.0031 & 0.0048 \\
\hline Third Kharitonov & 0.0075 & 0.0089 \\
\hline Fourth Kharitonov & 0.0349 & 0.042 \\
\hline
\end{tabular}

Therefore the step responses of the original and reduced order Kharitonov's transfer functions are shown in Figure 2, 3, 4, and 5 respectively.

Table 2. Typical parameter used by Differential Evolution for four Kharitonov's transfer functions.

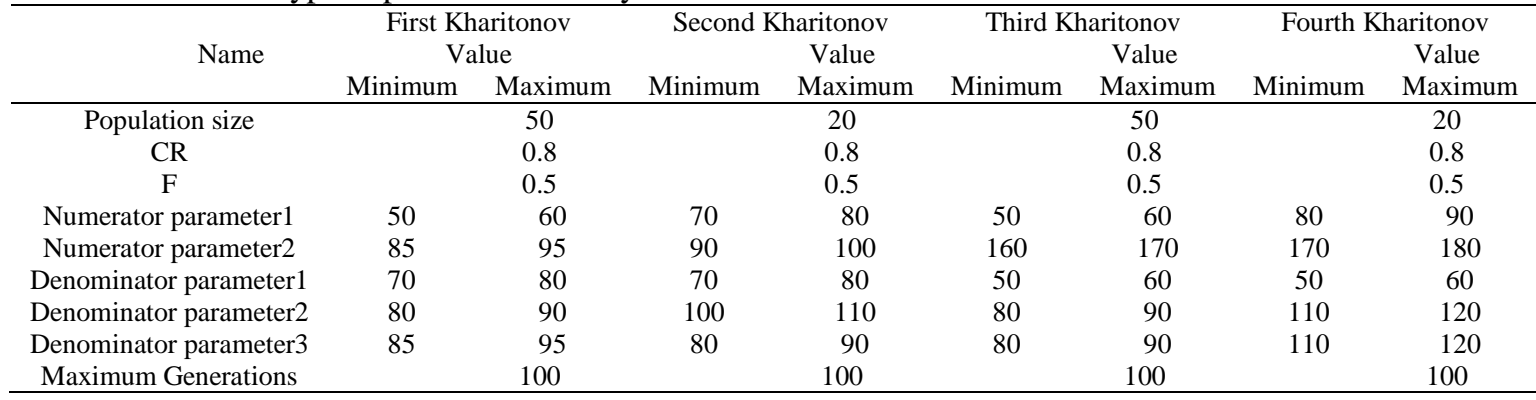

Table 3. Comparison of ISE for four Kharitonov polynomials. 


\subsection{Reduced Interval model}

Then the closed loop and open loop interval transfer functions model of reduced are obtained from the equations (42)-(45) and are represented as(45-46)

$$
\begin{aligned}
& \mathrm{T}_{\mathrm{k}}=\frac{[53.4014,84.9994] \mathrm{s}+[90.1511169 .9494]}{[50,79.4364] \mathrm{s}^{2}+[80,120] \mathrm{s}+[89.5829,169.9993]} \\
& \mathrm{G}_{\mathrm{k}}(\mathrm{s}, \mathrm{c}, \mathrm{d})=\frac{[53.4014,84.9994] \mathrm{s}+[90.1511,169.9494]}{\left[50,79.4364 \mathrm{~s}^{2}+[-4.9994,66.5986 \mathrm{~s}+[-60.3665,79.8482\right.}
\end{aligned}
$$

Here the open loop reduced order model is an unstable and closed loop reduced order model is stable. In order to improve the stability of this reduced order model, the PI/PID controller is required.

\subsection{Design of $P I$ controller:}

The transfer function of the PI controller is given by

$$
\mathrm{C}_{\mathrm{PI}}(\mathrm{s})=\mathrm{K}_{\mathrm{P}}+\frac{\mathrm{K}_{\mathrm{I}}}{\mathrm{s}}=\frac{\mathrm{N}_{\mathrm{c}}(\mathrm{s})}{\mathrm{D}_{\mathrm{c}}(\mathrm{s})}
$$

Then the closed loop transfer function with a PI controller becomes (47)

$$
T(s)=\frac{\left[53.4014 K_{P}, 84.9994 K_{P}\right] s^{2}+\left[90.151 K_{P}+53.4014 K_{I}, 169.9494 K_{P}+84.9994 K_{I}\right] s+}{\left[90.4014 K_{I}, 169.9494 K_{I}\right]}
$$

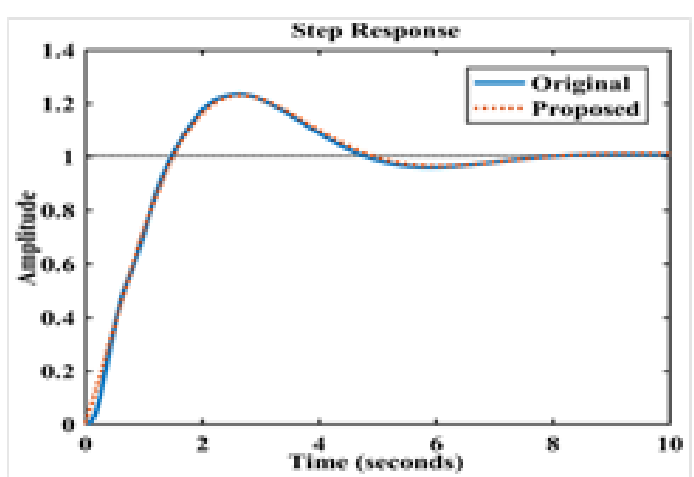

Figure 2. Step Responses for original higher order and its reduced order models for first Kharitonov transfer function

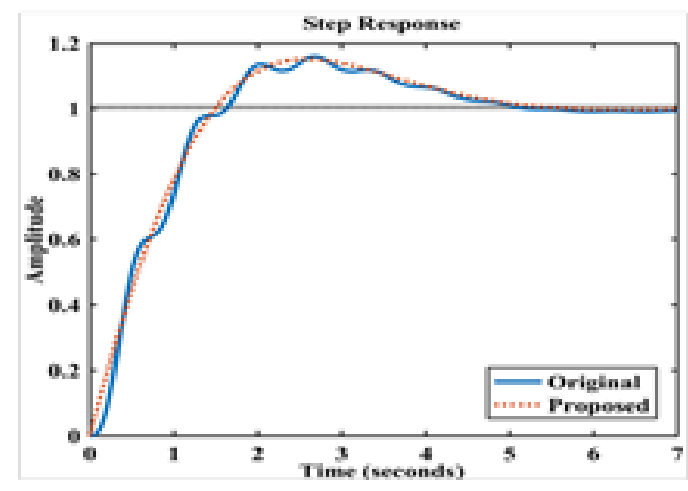

Figure 3. Step Responses for original higher order and its reduced order models for second Kharitonov transfer Function

From the above equation, the characteristic equation of the closed loop interval system with PI controller can be taken as (48)

$$
\begin{aligned}
& {[50,79.4364] \mathrm{s}^{3}+\left[53.401 \mathrm{~K}_{\mathrm{P}}-4.9994,84.9994 \mathrm{~K}_{\mathrm{P}}+66.598\right] \mathrm{s}^{2}+} \\
& {\left[90.151 \mathrm{~K}_{\mathrm{P}}+53.4014 \mathrm{~K}_{\mathrm{I}}-60.3665169 .9494 \mathrm{~K}_{\mathrm{P}}+84.9994 \mathrm{~K}_{\mathrm{I}}+79.8482\right] \mathrm{s}+\left[90.151 \mathrm{~K}_{\mathrm{I}}, 169.9494 \mathbf{K}_{\mathrm{I}}\right]=0}
\end{aligned}
$$

From the above equation, the nominal characteristic equation is (49) 


$$
\Delta(s)=s^{3}+\left(0.4759+1.0693 K_{P}\right) s^{2}+\left(0.1505+2.0095 K_{P}+1.0693 K_{I}\right) s+2.0095 K_{I}=0
$$

The optimal characteristic equation that minimizes the Integral Time Absolute Error (ITAE) performance for step input is given by [30] is (50)

$$
\Delta(s)=s^{3}+1.75 \omega_{n} s^{2}+2.15 \omega_{n}^{2} s+\omega_{n}^{3}=0
$$

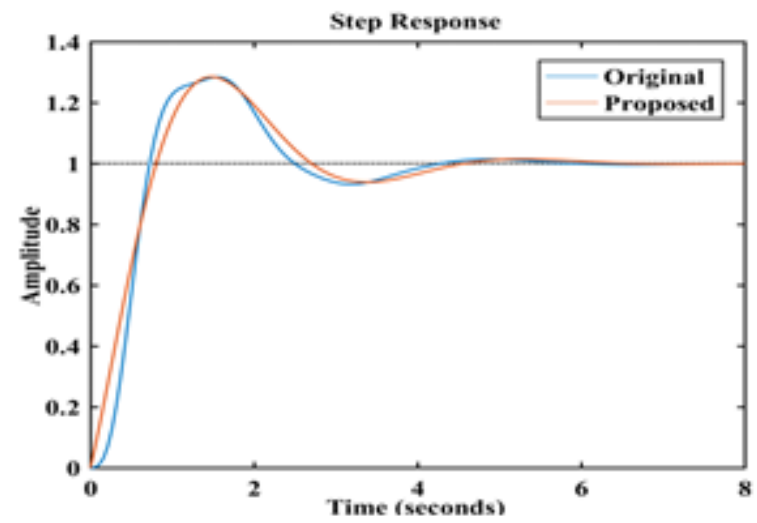

Figure 4. Step Responses for original higher order and its reduced order models for third Kharitonovtransfer function

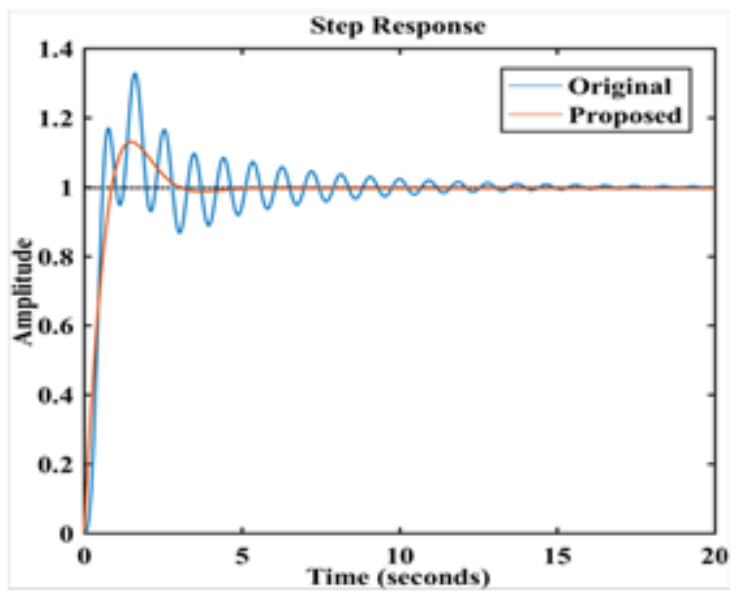

Figure 5. Step Responses for original higher order and its reduced order models for fourth Kharitonovtransfer Function

By comparing the above two equations (49) and (50), the nominal PI controller parameters as $\mathrm{K}_{\mathrm{P}}^{0}=0.9886$ and $\mathrm{K}_{\mathrm{I}}^{0}=0.3344$. The nominally designed PI controller is shown in Figure 6. This nominally designed PI controller is still unable to stabilize the whole closed-loop system under all possible parameter variations. It is therefore desired to redesign a robust PI stabilizing controller for this interval plant starting from its nominal one. By applying the necessary and sufficient conditions from the Table 1 of the equations for the above 3rd order polynomial of the equation (49), the following set of inequality constraints are obtained. In order to make this set of constraints into the feasible closed set, a small positive number ' $\varepsilon$ ' is introduced into the constraints. Hence the Non-Linear Programming (NLP) optimization problem stated as to find the controller parameters, $K_{P}$ and $K_{I}$ such that the objective function $J=\left(K_{P}-K_{P}^{0}\right)^{2}+\left(K_{I}-K_{I}^{0}\right)^{2}$ is minimized, subjected to the following constraints Inequality constraints for proposed method: 
Necessary conditions:

$$
\begin{aligned}
& -90.151 \mathbb{K}_{I}+\varepsilon<O \\
& -90.151 \mathbb{K}_{P}-53.4014 K_{I}+60.3665+\varepsilon<0 \\
& -53.4014 K_{P}+4.9994+\varepsilon<0
\end{aligned}
$$

Sufficient conditions:

$-\left(-60.3665+53.4014 K_{I}+90.151 K_{P}\right)^{2}+3 *\left(66.598+84.9994 K_{P}\right) * 1699494 K_{I}+\varepsilon<0$

The linear programming problem consists of two decision variables and four constraints. The controller parameters $\mathrm{K}_{\mathrm{P}}$ and $\mathrm{K}_{\mathrm{I}}$ are restricted to small values by choosing the objective function $\mathrm{J}$ properly. The purpose of using a small positive number $\varepsilon$ is to formulate a feasible set closed. In this work, the DE technique proposed in section 4 is used to minimize the objective function ${ }^{J}$ to determine the values of $\mathrm{K}_{\mathrm{P}}$ and $\mathrm{K}_{\mathrm{I}}$ they are tabulated in Table 4 . From the Table 4, it is observed that $K_{P}$ and $K_{I}$ values are increasing as ' $\varepsilon$ ' is increased. This represents the sensitivity of the controller with respect to $\varepsilon$. By applying the proposed algorithm, then the values of controller parameters are obtained as $\mathrm{K}_{\mathrm{P}}=0.7374$ and $\mathrm{K}_{\mathrm{I}}=0.0012$ with $\varepsilon=0.5$. As per rules of the model, the PI controller designed for reduced order is also stabilizes original higher order system. Hence the original higher order system is stabilized more by the PI controller from this proposed method for the reduced order system. The closed loop step response of the system with a PI controller for both proposed method ( $K_{P}=0.7374$ and $\left.K_{I}=0.0012\right)$ and the method given in [23] ( $K_{P}$ $=0.5$ and $K_{I}=0.1$ ) are shown in Figures 7 and 8 for $\varepsilon=0.5$ respectively. The time domain specifications of Figure 7 and 8 are shown in Table 5. The step response comparison of four extreme plants with a PI controller obtained by the proposed method and the method given in [23] is shown in Figure 9.

Table 4. Variation of $K_{P}$ and $K_{I}$ for different values of $\varepsilon$ for proposed method.

\begin{tabular}{cccc}
\hline Controller Set & $\varepsilon$ & $K_{1}$ & $K_{2}$ \\
\hline 1 & 0.5 & 0.7374 & 0.0012 \\
2 & 1 & 0.9256 & 0.0045 \\
3 & 1.5 & 1.1752 & 0.0094 \\
4 & 2 & 1.1961 & 0.01367 \\
\hline
\end{tabular}

\begin{tabular}{|c|c|c|c|c|c|c|c|c|}
\hline \multirow[b]{2}{*}{$\begin{array}{l}\text { Name of e } \\
\text { KharitonovPolynomial }\end{array}$} & \multicolumn{4}{|c|}{ Proposed method } & \multicolumn{4}{|c|}{ Existing method in [23] } \\
\hline & $\begin{array}{c}\text { \%peak } \\
\text { overshootMP }\end{array}$ & $\begin{array}{l}\text { Peak } \\
\text { Time } \\
\text { tp (sec) }\end{array}$ & $\begin{array}{c}\text { Rise } \\
\text { time } \\
\text { tr(sec) }\end{array}$ & $\begin{array}{c}\text { Settling } \\
\text { timets }(\mathrm{sec})\end{array}$ & $\begin{array}{c}\% \text { peak } \\
\text { overshootMP }\end{array}$ & $\begin{array}{l}\text { Peak } \\
\text { Time } \\
\text { tp(sec) }\end{array}$ & $\begin{array}{l}\text { Rise } \\
\text { time } \\
\operatorname{tr}(\mathrm{sec})\end{array}$ & $\begin{array}{c}\text { Settling } \\
\text { timets(sec) }\end{array}$ \\
\hline First & 14.6937 & 3.3096 & 1.3716 & 5.6396 & 32.4147 & 4.008 & 1.508 & 10.808 \\
\hline Second & 25.6613 & 2.5676 & 0.4562 & 5.0282 & 24.3994 & 2.488 & 0.880 & 8.2771 \\
\hline Third & 23.6792 & 3.1885 & 1.3010 & 8.3247 & 57.6729 & 3.820 & 1.378 & 26.828 \\
\hline Fourth & 30.7057 & 1.7341 & 0.5627 & 4.7373 & 42.659 & 2.166 & 0.741 & 8.326 \\
\hline
\end{tabular}

Table 5. Time domain specifications for Higher order system with PI controller for proposed method and the method in [23]

It has been observed from Figures 7 and 8 that the designed PI controller, which uses the proposed stability conditions, robustly stabilizes the plant very quickly when compared to the method given in [23]. From Table 5, the designed PI controller stabilizes the plant with lesser time domain parameters than the existing method. The proposed method involves four sets of equations for NLP to solve. Thus, the proposed method requires less computational complexity than the method given in the literature. Thus, the developed PI controller from proposed method is not only stabilizes the reduced order model, but also stabilizes the original higher order system. 


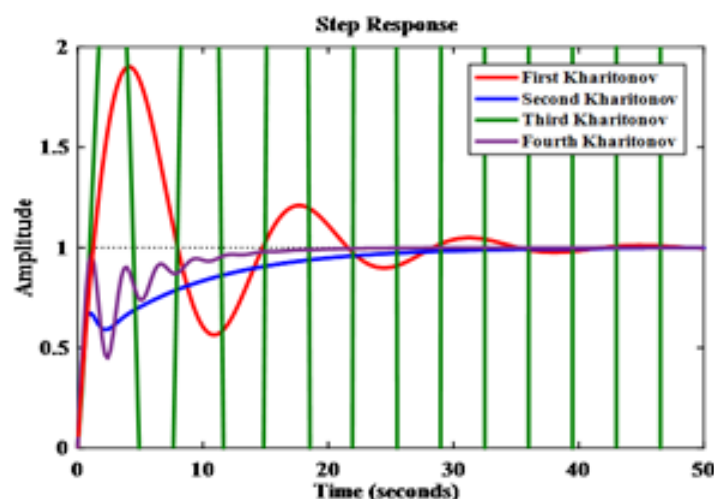

Figure 6. Time response to nominal PI controller design for conventional configuration

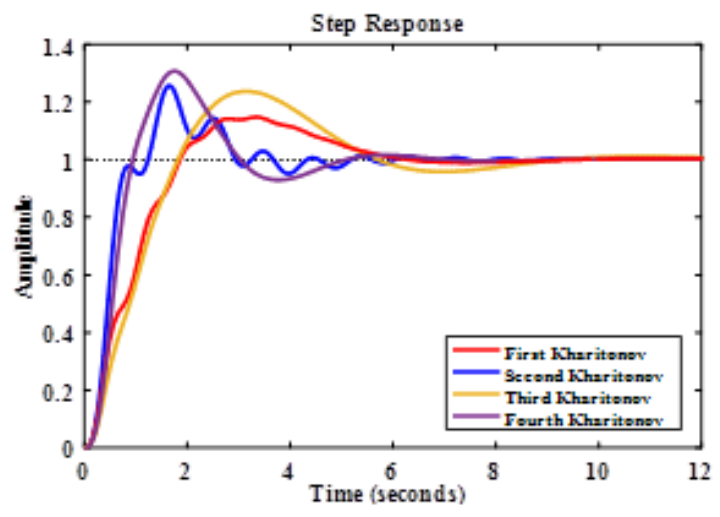

Figure 7. Time response of proposed interval system with PI controller with proposed method

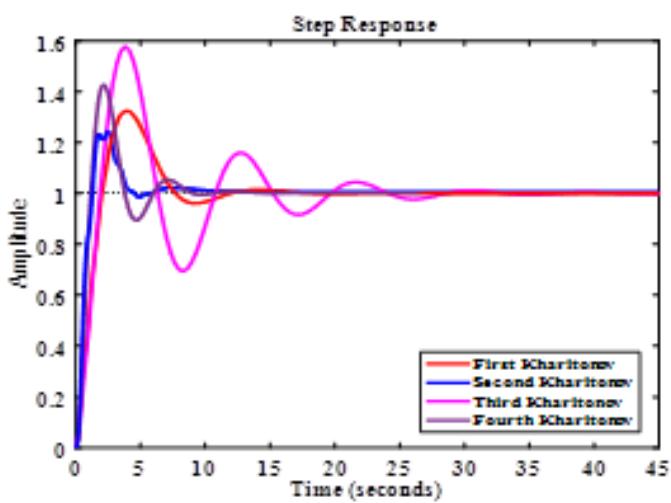

Figure 8. Time response of interval system with PI controller using the method [23]

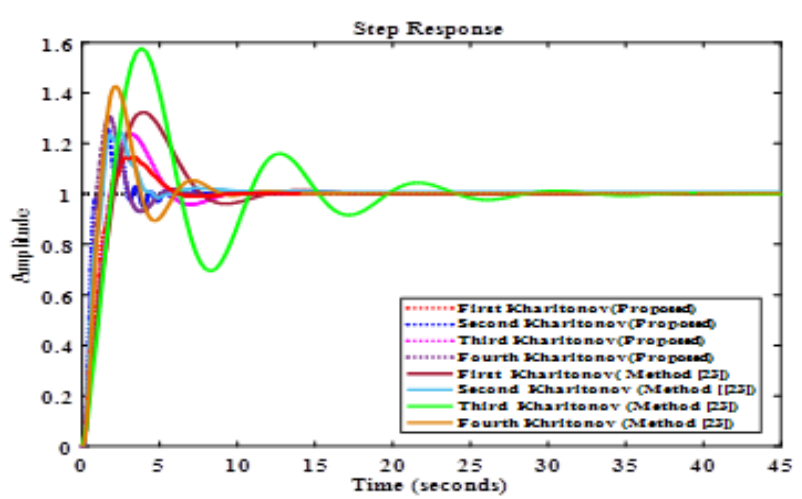

Figure 9. Time response comparison of interval system with the PI controller using proposed method and the method in [23]

\subsection{Design of PID controller:}

The transfer function of the PID controller is given by

$$
\mathrm{C}_{\mathrm{PI}}(\mathrm{s})=\mathrm{K}_{\mathrm{P}}+\frac{\mathrm{K}_{\mathrm{I}}}{\mathrm{s}}+\mathrm{K}_{\mathrm{D}} \mathrm{s}=\frac{\mathrm{N}_{\mathrm{c}}(\mathrm{s})}{\mathrm{D}_{\mathrm{c}}(\mathrm{s})}
$$

Then the closed loop transfer function with a PID controller becomes (51)

$$
T(s)=\frac{\left[53.4014 K_{D}, 84.9994 K_{D}\right] s^{3}+\left[90.1511 K_{D}+53.4014 K_{P}, 169.9494 K_{D}+84.9994 K_{P}\right] s^{2}+}{\left[50.1511 K_{P}+53.4014 K_{I}, 169.9494 K_{P}+84.9994 K_{I}\right] s+\left[90.4014 K_{I}, 169.9494 K_{I}\right]}
$$

From the above equation, the characteristic equation of the closed loop interval system with PI controller can be taken as (52)

$\left[50+53.4014 K_{D}, 79.4364+84.9994 K_{D}\right] s^{3}+\left[90.1511 K_{D}+53.4014 K_{P}-4.9994,169.9494 K_{D}+84.9994 K_{P}+66.598\right] s^{2}+$ $\left[90.1511 K_{P}+53.4014 K_{I}-60.3665169 .9494 K_{P}+84.9994 K_{I}+79.8482\right] s+\left[90.1511 K_{I}, 169.9494 K_{I}\right]$

From the above equation, the nominal characteristic equation is (53) 
$\Delta(s)=\left(64.7182+69.2004 K_{D}\right) s^{3}+\left(13005 K_{D}+69.2004 K_{P}+30.7996\right) s^{2}+\left(9.7407+13005 K_{P}+69.2004 K_{I}\right) s+13005 K_{I}=0$

By comparing the above two equations (50) and (53), the nominal PID control parameters as $\mathrm{K}_{\mathrm{P}}^{0}=1.3181 \mathrm{~K}_{\mathrm{I}}^{0}=1.77384_{\text {and }} \mathrm{K}_{\mathrm{D}}^{0}=0.4435$. The step response to the nominal PID controller is shown in Figure 10. This nominally designed PID controller is still unable to stabilize the whole closed-loop system under all possible parameter variations. It is therefore desired to redesign a robust PID stabilizing controller for this interval plant starting from its nominal one. By applying the necessary and sufficient conditions from the Table 1 of the equations for the above 3rd order polynomial of the equation (53), the following set of inequality constraints are obtained. In order to make this set of constraints into the feasible closed set, a small positive number ' $\varepsilon$ ' is introduced into the constraints. Hence the Non-Linear Programming (NLP) optimization problem stated as to find the controller parameters, $\mathrm{K}_{\mathrm{P}}, \mathrm{K}_{\mathrm{I}}$ and $\mathrm{K}_{\mathrm{D}}$ such that the objective function $J=\left(K_{P}-K_{P}^{0}\right)^{2}+\left(K_{I}-K_{I}^{0}\right)^{2}+\left(K_{D}-K_{D}^{0}\right)^{2}$ is minimized, subjected to the following constraints

Inequality constraints for proposed method:

Necessary conditions:

$$
\begin{aligned}
& -90.151 \mathbb{K}_{I}+\varepsilon<0 \\
& -90.151 K_{P}-53.4014 K_{I}+60.3665+\varepsilon<0 \\
& -90.151 \mathbb{K}_{D}-53.4014 K_{P}+4.9994+\varepsilon<0 \\
& -53.4014 K_{D}-50+\varepsilon<0
\end{aligned}
$$

Sufficient conditions:

$-\left(-60.3665+53.4014 K_{I}+90.151 K_{P}\right)^{2}+3 *\left(66.598+1699494 K_{D}+84.9994 K_{P}\right) * 1699494 K_{I}+\varepsilon<0$

The linear programming problem consists of three decision variables and five constraints. The controller parameters $\mathrm{K}_{\mathrm{P}}, \mathrm{K}_{\mathrm{I}}$ and $\mathrm{K}_{\mathrm{D}}$ are restricted to small values by choosing the objective function $\mathrm{J}$ properly. The purpose of using a small positive number $\varepsilon$ is to formulate a feasible set closed. In this work, the DE technique proposed in section 4 is used to minimize the objective function $J$ to determine the values of $\mathrm{K}_{\mathrm{P}}, \mathrm{K}_{\mathrm{I}}$ and $\mathrm{K}_{\mathrm{D}}$. They are tabulated in Table 6. From the Table 6, it is observed that $\mathrm{K}_{\mathrm{P}}, \mathrm{K}_{\mathrm{I}}$ and $\mathrm{K}_{\mathrm{D}}$ values are increasing as ' $\varepsilon$ ' is increased. This represents the sensitivity of the controller with respect to $\varepsilon$. By applying the proposed algorithm, then the values of controller parameters are obtained as $\mathrm{K}_{\mathrm{P}}=0.7879$, $\mathrm{K}_{\mathrm{I}}=0.0018$ and $\mathrm{K}_{\mathrm{D}}=0.1716$. As per rules of the model, the PI controller designed for reduced order is also stabilizes original higher order system. Hence the original higher order system is stabilized more by the PID controller from this proposed method for the reduced order system. The closed loop step responses of the system with a PI controller for both proposed method ( $\mathrm{K}_{\mathrm{P}}=0.7879,{ }^{\mathrm{K}_{\mathrm{I}}}=0.0018$ and $\left.\mathrm{K}_{\mathrm{D}}=0.1716\right)$ and the method given in [23] $\left(K_{P}=0.5,{ }^{K}=0.1\right.$ and $\left.K_{\mathrm{D}}=0\right)$ are shown in Figures 8 and 11 for $\varepsilon=0.5$ respectively. The time domain specifications of Figure 8 and 11 are shown in Table 7. The step response comparison of four extreme plants with the PID controller obtained by the proposed method and the method given in [23] is shown in Figure 11.

Table 6. Variation of $K_{P}, K_{I}$ and $K_{D}$ for different values of $\varepsilon$ for the proposed method.

\begin{tabular}{ccccc}
\hline Controller Set & $\varepsilon$ & $K_{p}$ & $K_{i}$ & $K_{D}$ \\
\hline 1 & 0.5 & 0.7898 & 0.0018 & 0.1716 \\
2 & 1 & 0.9962 & 0.0034 & 0.2538 \\
2 & 1.5 & 1.2308 & 0.0084 & 0.2780 \\
4 & 2 & 1.2782 & 0.0092 & 0.2954 \\
\hline
\end{tabular}

IJRA, Vol. 7, No. 4, December 2018: $232-250$ 
Table 7. Time domain specifications for Higher order system with Proposed PID controller for proposed method and the method in [23]

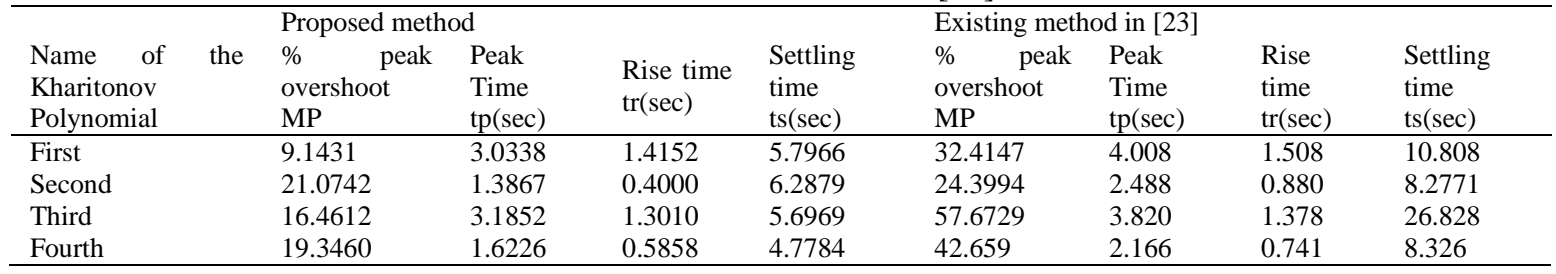

It has been observed from Figures 12 and 8 that the designed PID controller, which uses the proposed stability conditions, robustly stabilizes the plant very quickly when compared to the method given in [23]. From Table 7, the designed PID controller stabilizes the plant with lesser time domain parameters than the existing method [23]. The proposed method involves five sets of equations for NLP to solve. Thus, the proposed method requires less computational complexity than the method given in the literature. Thus, the developed PID controller from proposed method is not only stabilizes the reduced order model, but also stabilizes the original higher order system.

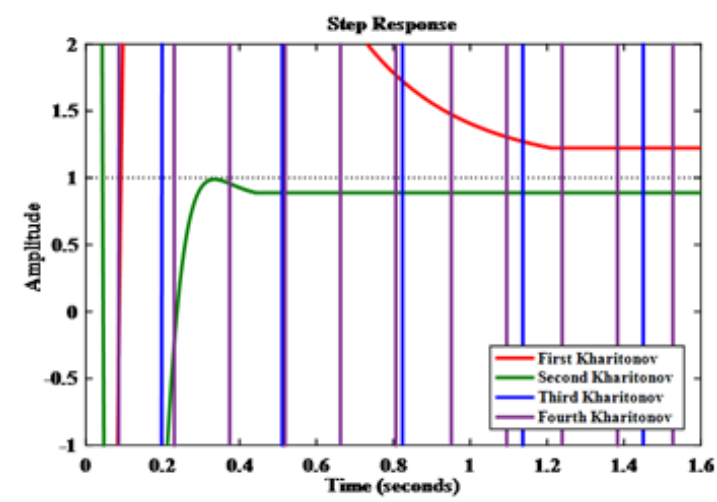

Figure 10. Time response to nominal PID controller design for proposed configuration

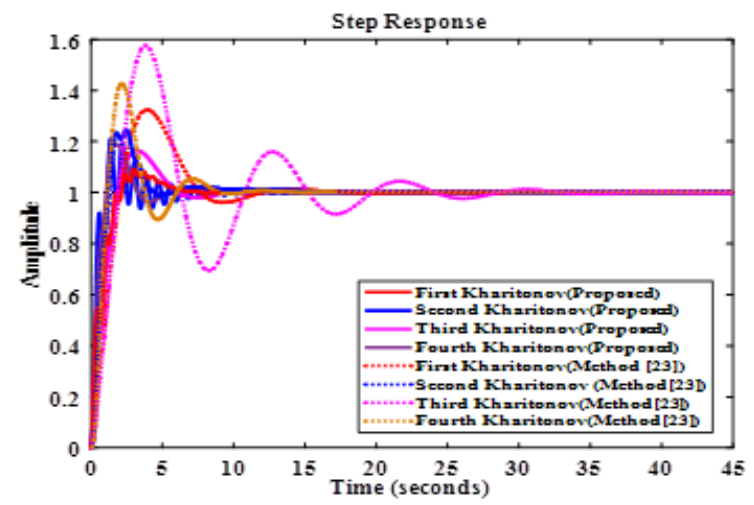

Figure 11. The time response of interval system with PID controller using the method [23] 


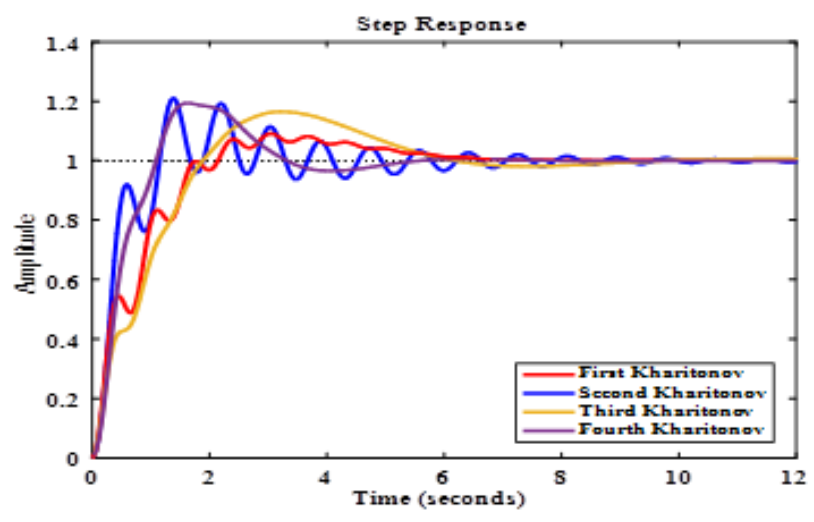

Figure 12. Time response of proposed interval system with PID controller

\section{CONCLUSIONS}

This paper proposes the design of the robust PI/PID controller for higher order interval systems using the differential evolution (DE) algorithm. In this paper, a stable reduced interval model is obtained from a higher order interval system using the DE. This reduced order interval numerator and denominator polynomials are determined by using the Kharitonov's theorem with the minimization of Integral Squared Error using the DE. Then for this lower order interval model, a robust PI/PID controller is designed based on the stability conditions for determining robust stability of interval systems with the help of DE. Finally, these stability conditions are used to derive a set of inequalities in terms of controller parameters and these inequalities are solved to obtain a robust controller with the help of a DE algorithm for an unstable interval plant. This designed PI/PID controller for the reduced order model stabilizes the higher order system. The proposed PI/PID controller procedure is also applied and demonstrated through a typical numerical example. It has been observed from the simulation results that the designed PI/PID controller for the reduced order model robustly stabilizes the higher order plant with lesser time domain parameters than the existing method. The simulation results are evidence for its robustness in stabilizing the interval process using a PI/PID controller. Hence we conclude that the designed PI/PID controller obtained from proposed method stabilizes the plant superior than the methods available in the literature. Also, the proposed method is simple and involves less computational complexity in comparison with the methods available in the literature.

\section{REFERENCES}

[1] M.Aoki, "Control of Large-Scale Dynamic Systems by Aggregation," IEEE Trans. on automatic control, vol.13, no. 3, pp.246-253,1968.

[2] Y. Shamash, "Stable reduced order models using Pade type approximation," IEEE Trans. Automat. Contr., vol.19, no.5, pp. 615-616, 1974.

[3] M. F. Hutton and B. Friedland. "Routh approximation for reducing order of a linear time invariant system," IEEE Trans. Automat. Contr., vol.20, no.1, pp. 329-337, 1975

[4] Y. Shamash, "Model reduction using Routh stability criterion and the Pade approximation," Int. J. Contr., vol. 21, no.3, pp. 475484, 1975.

[5] A.S. Rao, S.S. Lamba and S.V. Rao "Routh-approximant time-domain reduced order modelling for single-input and single-output systems, 'IEE Proc., Control theory, application, vol.125, no.10, pp.1059-1063,1978.

[6] G.Vasu,M.Siva Kumar. and M.Ramalinga Raju, "a novel method for optimal simplification of large scale linear discrete-time systems", Int. J. Automation and Control, Vol.10,No.2, pp.120-141,2016.

[7] G.Vasu, M.Siva Kumar and M.Ramalinga Raju. "Optimal least square model approximation for large scale linear discrete-time systems", Trans. of the institute of Measurement and Control,Vol.40,No.1,pp.35-48,2018.

[8] B. Bandyopadhyay, O. Ismail, and R. Gorez, "Routh-Pad'e approximation for interval systems," IEEE Trans. Automat. Contr., vol. 39, no.12,pp. 2454-2456, 1994.

[9] Hwang C. And Yang S.F, "comments on the computations of interval Routh Approximants,"IEEE Trans. Automat. Contr., vol. 44, no.9, pp. 1782-1787, 1999.

[10] M. Siva Kumar and Gulshad Begum, "Model Order Reduction of Linear Time Interval System Using Stability Equation Method and a Soft Computing Technique," advances in Electrical and Electronic Engineering, vol. 14, no. 2, pp.153-161, June- 2016. 
[11] M. Siva Kumar, N. Vijaya Anand and R. Srinivasa Rao, "Impulse energy approximation of higher-order interval systems using Kharitonov's polynomials," Transactions of the Institute of Measurement and Control Vo.1,no.11,pp.1-11,2015.

[12] D. Kranthi Kumar, S. K. Nagar and J. P. Tiwari, "Model Order Reduction of Interval Systems UsingMihailov Criterion and Routh Approximations," International journal of engineering science and technology, Vol. 3 no. 7, pp. 5593-5598, July 2011.

[13] B. R. Barmish, “A generalization of Kharitonov's four polynomial concept for robust stability problems with linearly Dependent coefficient perturbations, "IEEE Trans. Automatic Control, vol. 34, no.2, pp. 157- 165, 1989.

[14] M.R.Chidambara and R.B.Schainkar, "Lower order generalized aggregated model and sub-optimal control," IEEE Trans.Automa.Control, vol.16, no.2, pp.175-180, 1971.

[15] R.N. Mishra, 'Design of Low-order control Scheme using reduction technique," Int.J.Control, vol.32 no.5, pp.899-906, 1980.

[16] S.S.Lamba and S.V.Rao, "Suboptimal control linear systems via simplified models of Davison," IEEE Trans. Automa. Control, Vol.19, no.4, pp.448-450, 1974.

[17] P.Oliver,"On the relationship between model order reduction problem," IEEETrans.Automa Control, vol.32,no.1,pp.54-55,1987.

[18] A. Linnemann, "Existence of controllers stabilizing the reduced-order model and not the plant," Automatica, vol.24,no.5,pp.719,1988.

[19] B.Bandyopadhyay,H. Unbehauen and B.M. Patre, (1998) "Control of higher order system via its reduced model", TENCON '98. IEEE Region 10 International Conference on Global Connectivity in Energy, Computer, Communication and Control, New Delhi,India,17-19 Dec..1998.

[20] T.Alamirew,V. Balaji and N. Gabbeye "Comparison of PID controller with model predictive controller for milk pasteurization process", Bulletin of Electrical Engineering and Informatics, vol.6,no.1,pp.24-35,March 2017.

[21] Mohammad Bakhshipour, Farhad Namdari and Nooshin Bahador, "New Hybrid Non-Dominated Sorting Differential Evolutionary Algorithm", Bulletin of Electrical Engineering and Informatics,vol.5, no.2, pp.230241.June 2016.

[22] Kim seng Chia, "Ziegler-Nichols Based Proportional-Integral-Derivative Controller for a Line Tracking Robot," Indonesian journal of electrical engineering and computer science, vol.9, no.1, pp.221-226,Jan.2018.

[23] Patre, B.M. \& Deore, P.J. (2003). Robust Stabilization of Interval Plants', European Control Conf. ECC-03, University of Cambridge (UK), pp.1660-1663.

[24] Kalyani, T. and Siva Kumar, M "Computational of optimal stabilizing PID controller for interval plants using PSO,” International Journal Engineering Research. and Technology.,vol.2, no.10.2013.

[25] B.M. Patre and P.J.Deore, "Robust stability and performance for interval process plants," ISA transactions, vol.46, no.3, pp.343-349, June 2007.

[26] Nie, Y.Y. (1976) "A new class of criterion for the stability of the polynomial," Act. Mechnica sinica, vol.15. no.1, pp. 110-116.

[27] R.Storn and K.Price, "Differential Evolution - A Simple and Efficient Heuristic for Global Optimization over Continuous Spaces, ” Journal of Global Optimization, vol.11, no.4, pp. 341-359, 1997.

[28] D. Srinivasa Rao, M. Siva Kumar and M. Ramalinga Raju, "New algorithm for the design of robust PI controller for plants with parametric uncertainty," Transactions of the Institute of Measurement and Control, vol.40, no.5, pp.1481-1489,2018.

[29] B.D.O.Anderson, E.I.Jury and M.Mansour, "On Robust Hurwitz polynomials," IEEE Trans. on Automatic controls, vol.32, no.10, pp.909-913, Oct.1987.

[30] R-C Dorf and R-H Bishop, "Modern control systems," $12^{\text {th }}$ ed., pear Education, Inc., Upper Saddle River, New Jersey, pp.322-339,2011.

\section{BIOGRAPHIES OF AUTHORS}

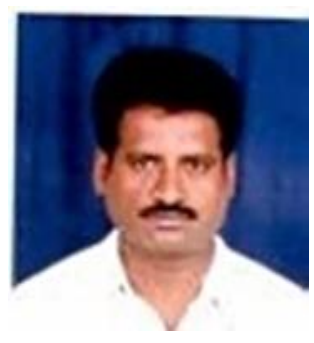

D. SRINIVASA RAO received his B. Tech. Degree in Electrical and Electronics Engineering from J.N.T.U College of Engineering, Kakinada in 1993 and M.Tech degree from NIT Wangal, in Electrical Machines and Industrial Drives in 2003.Presently he is pursuing Ph.D. in J.N.T University Kakinada. His area of interest includes model order reduction, controller design, Electrical Machines and Power Electronics. 


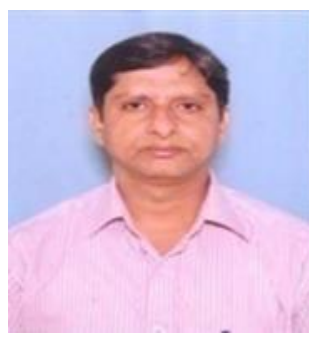

Mangipudi Siva Kumar was born in Amalapuram, E.G. Dist, Andhra Pradesh, India, in 1971. He received a bachelor's degree in Electrical \& Electronics Engineering from JNTU College of Engineering, Kakinada and M.E and Ph.D degree in control systems from Andhra University College of Engineering, Visakhapatnam, in 2002 and 2010 respectively. His research interests include model order reduction, interval system analysis, and design of PI/PID controllers for Interval systems, sliding mode control, and soft computing techniques. Presently he is working as Professor and H.O.D of Electrical Engineering department, Gudlavalleru Engineering College, Gudlavalleru, A.P, India. He received best paper awards at several national conferences held in India.

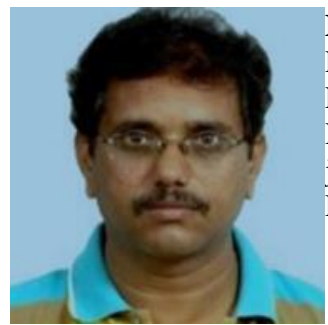

M.Ramalinga Raju graduated in 1986 from JNTU, Masters in 1989 from REC, Warangal and Received Ph.D. degree in 2004 from JNT University, INDIA. Presently he is working as Professor and Director for Admissions, University College of Engineering Kakinada, JNTUK. He presented many research papers in various national and international conferences and journals. His research interests include Energy Management, Conservation and Auditing, Distributed Generation and IT Applications in Power Utility Companies 